Christiansen, N. D., Quirk, S. W., Robie, C., \& Oswald, F. L. (2014). Light Already Defines the

Darkness: Understanding Normal and Maladaptive Personality in the Workplace. Industrial and Organizational Psychology, 7(1), 138-143. doi:10.1111/iops.12122

\title{
Light Already Defines the Darkness: Understanding Normal and Maladapive Personality in the Workplace
}

\author{
Neil D. Christiansen and Stuart W. Quirk \\ Central Michigan University \\ Chet Robie \\ Wilfrid Laurier University \\ Frederick L. Oswald \\ Rice University
}

In the focal article, Guenole (2014) calls for the psychology of work to embrace a new trait model that more directly incorporates maladaptive tendencies found in contemporary research on psychopathology, namely the traits assessed in the Personality Inventory for DSM5 (PID-5). Although this proposition has merit in the abstract, a number of issues arise for industrial-organizational (I-O) psychologists who might consider this model in the context of staffing efforts such as development or selection. For example, how can such maladaptive traits be linked to essential job functions and incorporated into personality-based job analysis? Certainly, maladaptive traits might be damaging to any occupation at their clinical extremes (such people may not be capable of even applying for a job), but in terms of applicants and employees with subclinical levels of maladaptive traits, determining their implications for the occupation is critical. Or as another practical example, how might current employees or applicants react when given an assessment of maladaptive traits or feedback on the results of such an assessment? We know that reactions to personality inventories are generally negative (McFarland, 2013) and we can only imagine that using more clinically oriented items or scale names might exacerbate the problem. To offer a third example, what ethical and legal concerns might arise when scores on maladaptive traits are used for staffing?

These challenges to implementation (and likely others) are important to address, but in the end the benefits of maladaptive trait assessment must be worth the potential costs incurred. As far as benefits, it is important to determine whether scores on maladaptive trait assessments explain incremental variance in important work outcomes beyond scores on assessments of normal personality that are better understood and already in standard use. Although such incremental validity for clinical measures has been demonstrated when predicting diagnoses of 
abnormal personality types (Thimm, 2011), there is very little supportive evidence for incremental validity for predicting work behavior and outcomes.

\section{Evidence of Incremental Validity}

The incremental validity of maladaptive personality measures predicting workplace behavior is likely to be scant because there is considerable overlap between the item content and factors underlying established measures of both normal and abnormal personality functioning. For example, De Fruyt et al. (2013) conducted a joint factor analysis of the NEO-PI-3 measure of normal personality (Hoekstra \& De Fruyt, 2013) and the PID-5 measure of psychopathology (Krueger, Derringer, Markon, Watson, \& Skodol, 2012), concluding that the Five-Factor Model (FFM) of normal personality adequately accounted for the covariance between scales from both measures. Watson, Stasik, Ro, and Clark (2013) and Ashton, Lee, de Vries, Hendrickse, and Born (2012) reached a similar conclusion based on their multivariate analyses of measures of normal personality (FFM and HEXACO measures) and psychopathology (the latter including the PID-5). To the extent that measures of normal personality overlap with measures of maladaptive personality, it will obviously be more difficult for the latter measures to explain incremental variance in work criteria beyond the former. We are reminded of a quote by Widiger, Costa, and Samuel (2006, p. 311):

\footnotetext{
Instruments to assess general personality structure can provide a more comprehensive assessment than instruments confined to the assessment of personality disorders, and the actual boundary between adaptive and maladaptive personality functioning is, at best, unclear.
}

Saying there is a lack of evidence for the incremental validity for measures of maladaptive traits does not mean such scores are not related to workplace criteria. For example, De Fruyt et al. (2009) showed that scores constructed to reflect personality disorders (PDs) from the NEO PI-R (Costa \& McCrae, 1992) and scores on the maladaptive traits from the Hogan Development Survey (HDS; Hogan \& Hogan, 1997) predicted selection decisions (based on other assessments) across a variety of samples. Harms, Spain, and Hannah (2011) found that subclinical traits impacted leadership development over time among military cadets. Benson and Campbell (2007) demonstrated that scores on maladaptive traits measured by the HDS were correlated with a range of leader behaviors rated by observers. However, studies such as these do not consider whether the same could be achieved by one of the many personality inventories already in use that we know will yield scores highly correlated with these maladaptive or "dark side" traits. Absent such evidence, why reinvent the wheel?

The most compelling evidence of incremental validity was recently reported by Wille, De Fruyt, and De Clercq (2013) and even here the research must be interpreted with caution. Using 7 to 17 FFM scores on personality facets (narrow traits), these researchers constructed composite scores reflecting PDs; they then used these composites to predict career outcomes of college alumni. Not only did many of these composites (e.g., Schizotypal, Avoidant, and Borderline) correlate with later work outcomes, these researchers did examine whether the composites predicted beyond scores on the five broad FFM traits. However, given the way the PD scores were derived, it is unclear whether the incremental variance over FFM scores was due to the composites actually capturing maladaptive levels of behavior or whether it was simply because maladaptive composites contain different combinations of specific facets than FFM composites, thus allowing some of the specific facets in the maladaptive composites to provide more 
prediction of outcomes than these same facets in the FFM composites. Conducting regression analyses from the facet-level composites would have helped to clear up these alternative interpretations, as prediction and understanding afforded from facet-level measures can get diluted from analyses at the broad factor level. However in this case, it would have been mathematically impossible to show the PD compound traits explained variance beyond the very facets used to compute them. To demonstrate the benefits of using personality facets for predicting work outcomes, Christiansen and Robie (2011) found that analysis at the level of facet scales (even after correcting for capitalization on chance) explains an additional $5 \%$ to $10 \%$ of the variance in job performance beyond FFM composite scores.

This gives rise to the question of whether composites of FFM facet scales obscure understanding of the facets and whether they adequately represent subclinical traits related to personality pathology. Although FFM facets have been shown to be useful for explaining psychopathology (e.g., Quirk, Christiansen, Wagner, \& McNulty, 2003; Samuel \&Widiger, 2008), composite scores do not exactly reflect the way symptoms are assessed to make psychiatric diagnoses. Composite scores of aberrant personality are compensatory in nature: given a particular score, one often cannot tell which specific facets typically associated with the PD were elevated. Being very high or very low on just one or two facets can therefore balance out having facet scores in the opposite direction on the rest in terms of what is typically associated with the PD. However, in the psychiatric assessment of PDs, there must be a preponderance of symptoms present (e.g., five of seven symptoms). We suggest investigating the incremental benefit of scores based on profile matching approaches that might better reflect whether there are configural (multiplicative) effects present. This might be approached by investigating the interactions of FFM facets without resorting to any maladaptive framework (Shoss \& Witt, 2013).

\section{Lack of Consensus on Framework for Maladaptive Traits}

Within the area of personality pathology, there continues to be disagreement on how to best represent the dimensionality of such traits (see the edited volume by Strack, 2006 for an appreciation of the diversity of approaches). Although Guenole's focal article does not discuss the controversy surrounding the process with which the PID-5 framework was derived, it has generated considerable discord in that community of researchers. Blashfield and Reynolds (2012) conducted a social network analysis showing that a relatively exclusive group of researchers was involved in its development (the DSM-5 Personality and Personality Disorders Work Group or PDWG). As noted by Lilienfeld, Watts, and Smith (2012) this may have led to the omission of the representatives of prominent alternative perspectives including FFM advocates and proponents of the Personality Psychopathology (PSY-5) that bears close resemblance to the DSM-5 trait dimensions (e.g., Harkness \& McNulty, 1994).

So even if maladaptive traits were found to have additional usefulness, it is unclear what framework to adopt. Lilienfeld et al. (2012, p. 831) stated that " . . . these and other omissions may inadvertently convey the impression that the PDWG is unduly ahistorical and insufficiently inclusive of previous theoretical and methodological perspectives.' The PID-5 that was the result of the efforts of this group, a clinical instrument designed to assist in psychiatric diagnosis of PD, was not intended to be a comprehensive personality assessment. The PID-5 as it is currently formulated may thus be viewed as "old wine in new bottles" (Sarup, 1978). There is also the risk of "jangle fallacies," where it is erroneously concluded that measures with different 
names assess different constructs when in fact what is measured is very similar or identical (Hartley, 1967; Kelly,1927). The danger here is that a framework that appears new might only end up proliferating trait labels and end up hindering research progress by making it difficult to draw cumulative inferences across normal and maladaptive trait frameworks.

\section{Understanding Personality and Dysfunctional Work Behavior}

The search for individuals with profoundly maladaptive tendencies but otherwise normal personality traits, which is what would be necessary for incremental validity, would seem to be tilting at windmills. Such individuals are probably exceedingly rare if they exist at all. Instead we suggest additional research effort aimed at the prediction of specific dysfunctional behaviors of interest to organizations using comprehensive personality assessments that comprise narrow traits. Suppose that the tendency toward micromanagement is of concern. Researchers should measure it in the workplace and identify the facets (and possible interactions) that predict those behaviors. If a compound scale is desired, it can then be computed from items or facets for future use when criterion data might not be available. Such research should adopt an interactionist perspective whenever possible in order to identify the situations that provide cues for trait expression (see e.g., Christiansen \& Tett, 2008; Tett, Simonet, Walser, \& Brown, 2013). This is important for understanding when such dysfunctional behavior is likely to occur and because it is sometimes possible to alter work situations to minimize the risk of such occurrences.

\section{Ethical and Legal Obstacles}

Even if incremental validity was shown with regard to work criteria, there are additional ethical and legal implications involved in the assessment of maladaptive traits. One aspect is the use of clinical personality assessments (e.g., PID-5) on populations or for purposes that differ from those they were developed for. Personality pathology inventories were designed and validated on individuals seeking treatment and were intended for diagnostic work that would lead to that treatment. Another potential ethical issue revolves around the training of the psychologists who would be giving the assessments, have access to the results, and be providing feedback to those who have been tested. Put simply, many I-O psychologists do not have adequate training with such tests and there may be legal ramifications if used without licensure (APA, 2010).

As mentioned briefly by Guenole, there are important implications with regard to psychological disabilities when scores on maladaptive traits are obtained because of the possibility that the assessment may be deemed a medical examination by the courts (see Karraker v. Rent-A-Center, 2005). The Americans with Disabilities Act of 1990 (and similar legislation in other countries) generally allows for medical examinations only after a conditional job offer has been made, and personality assessments are sometimes considered a medical examination. Using assessments targeting maladaptive traits prior to a conditional offer may be especially questionable from a legal standpoint because someone with a psychological disability could be negatively affected when in fact reasonable accommodation could have been made. Some of these ethical concerns would still be relevant if maladaptive traits were assessed using inventories such as the NEO PI-R to construct composites to represent the maladaptive traits discussed by Guenole. Taken together, this leads to a dead-end for a practitioner: The use of a clinical inventory to assess PDs is more likely to be viewed as a medical exam, whereas deriving 
maladaptive trait scores from inventories of normal personality are unlikely to add to prediction, even if they were deemed acceptable. Additionally, in neither case would the tests have been developed specifically for the "prediction of performance" as Guenole noted is important for withstanding legal scrutiny. Practitioners would therefore be well-advised to steer clear of any scales or composites named after an existing diagnosis, potentially including those from tests of normal personality labeled as Neuroticism (Schmit \& Ryan, 2013). Jones and Arnold (2008) suggest replacing items with obvious relationships to clinical diagnoses such as depression (e.g., "'I often feel blue'), anxiety (e.g., "I panic easily"), or bipolar disorder (e.g., "I change my mood a lot'') with content that refers directly to behavior at work.

Finally, there may be legal issues related to the right to privacy of incumbents and applicants when using maladaptive trait measures. In the United States, many state constitutions acknowledge that individuals should be able to control information about their thoughts, speech, and actions when the disclosure may cause discomfort or distress. Privacy laws can be even stronger in other countries, particularly in Europe (Myors et al., 2008). To some extent, all personality inventories inquire about areas that have this potential to offend. However, measures explicitly designed to assess maladaptive traits contain items an applicant is likely to find intrusive in much greater proportions (e.g., "I have trouble telling the difference between dreams and real life," "I often feel like a failure," "I normally can't control what I think about'). Following cases such as Soroka v. Dayton Hudson Corporation (1991) that focused on items involving applicants' religious beliefs and sexual proclivities, inventories such as MMPI-2 and PID-5 have generally avoided those specific topics but some related items can still be found (e.g., "'I'm not interested in having sexual relationships'), From a legal perspective, intrusive inquiries require a balance between individuals' rights to privacy and a compelling interest of the organization. Public safety often meets that burden and courts have at times accepted evidence that test scores are statistically related to job outcomes (Stabile, 2002). However, to be truly compelling it may require a demonstration that the clinical measure predicts better than scores from a normative personality inventory with far fewer invasive items.

\section{Conclusions}

In contrast to the opinion in the focal article, extraordinary progress has been made in the past 20 years toward understanding personality in the workplace using assessments of normative personality (Christiansen \& Tett, 2013). For example, research has investigated advantages of expanding the criterion domain of job performance when using personality traits as predictors to include citizenship (Organ \& Ryan, 1995) and counterproductive work behavior (Collins \& Schmidt, 1997). Personality variables have emerged as moderators of important relationships, such as between stressors and strains (Moyle, 1995). Other studies have found evidence of mediators of relationships between personality traits and work outcomes (e.g., Fritzsche, McIntire, \& Yost, 2002; Judge, Bono, \& Locke, 2000). In summary, personality and work has emerged as a vigorous research area and we should not risk "derailment" by abandoning the normative personality perspective that has worked so well. 


\section{References}

American Psychological Association (APA). (2010). American Psychological Association Ethical Principles of Psychologists and Code of Conduct. Retrieved August 9, 2013, from http://www.apa.org/ethics/code/principles.pdf

Americans with Disabilities Act of 1990. (1990). Retrieved August 8, 2013, from http://www.ada.gov/pubs/ada.htm

Ashton, M. C., Lee, K., de Vries, R. E., Hendrickse, J., \& Born, M. P. (2012). The maladaptive personality traits of the personality inventory for DSM-5 (PID-5) in relation to the HEXACO personality factors and schizotypy/dissociation. Journal of Personality Disorders, 26, 641-659.

Benson, M. J., \& Campbell, J. P. (2007). To be, or not to be, linear: An expanded representation of personality and its relationship to leadership performance. International Journal of Selection and Assessment, 15(2), 232-249.

Blashfield, R. K., \& Reynolds, S.M. (2012). An invisible college view of the DSM-5 personality disorder classification. Journal of Personality Disorders, 26, 821-829.

Christiansen, N. D., \& Robie, C. (2011). Further consideration of the use of narrow trait scales. Canadian Journal of Behavioural Science, 43,183-194.

Christiansen, N. D., \& Tett, R. P. (2008). Toward a better understanding of the role of situations in linking personality, work behavior, and job performance. Industrial and Organizational Psychology: Perspectives on Science and Practice, 3, 312-316.

Christiansen, N. D., \& Tett, R. P. (2013). The long and winding road: An introduction to the handbook of personality at work. In N. D. Christiansen, \& R. P. Tett (Eds.), Handbook of personality at work (pp.1-7). New York, NY: Routledge.

Collins, J. M., \& Schmidt, F. L. (1997). Can suppressor variables enhance criterion-related validity in the personality domain? Educational and Psychological Measurement, 57, 924-936.

Costa, P. T., Jr., \& McCrae, R. R. (1992). Revised NEO Personality Inventory (NEO PI-R) and NEO Five- Factor Inventory (NEO-FFI) professional manual. Odessa, FL: Psychological Assessment Resources.

De Fruyt, F., De Clercq, B., De Bolle, M., Willie, B., Markon, K., \& Krueger, R. F. (2013). General and maladaptive traits in a five-factor framework for DSM-5 in a university student sample. Assessment, 20, 295-307.

De Fruyt, F., De Clercq, B. J., Miller, J., Rolland, J., Jung, S., Taris, R., ... Van Hiel, A. (2009). Assessing personality at risk in personnel selection and development. European Journal of Personality, 23, 51-69.

Fritzsche, B. A., McIntire, S. A., \& Yost, A. P. (2002). Holland type as a moderator of personality performance predictions. Journal of Vocational Behavior, 60, 422-436.

Guenole, N. (2014). Maladaptive personality at work: Exploring the darkness. Industrial and Organizational Psychology: Perspectives on Science and Practice, 7(1), 85-97.

Harkness, A. R., \& McNulty, J. L. (1994). The Personality Psychopathology Five (PSY-5): Issue from the pages of a diagnostic manual instead of a dictionary. In S. Strack, \& M. Lorr (Eds.), Differentiating normal and abnormal personality (pp. 291-315). New York, NY: Springer.

Harms, P. D., Spain, S. M., \& Hannah, S.T. (2011). Leader development and the dark side of 
personality. Leadership Quarterly, 22, 495-509.

Hartley, E. L. (1967). Attitude research and the jangle fallacy. In C. W. Sherif, \& M. Sherif (Eds.), Attitude, ego-involvement and change (pp. 88-104). New York, NY: Wiley \& Sons.

Hoekstra, H. A., \& De Fruyt, F. (2013). NEO-PI-3Persoonlijkheidsvragenlijst [NEO-PI-3 personality inventory]. Manuscript in preparation.

Hogan, R., \& Hogan, J. (1997). Hogan Development Survey manual. Tulsa, OK: Hogan Assessment Systems.

Jones, J. W., \& Arnold, D. W. (2008). Protecting the legal and appropriate use of personality testing: A practitioner perspective. Industrial and Organizational Psychology: Perspectives on Science and Practice, 1, 296-298.

Judge, T. A., Bono, J. E., \& Locke, E. A. (2000). Personality and job satisfaction: The mediating role of job characteristics. Journal of Applied Psychology, 85, 237-249.

Karraker v. Rent-A-Center. 411 F.3d 831, 833 (7th Cir.2005).

Kelly, T. L. (1927). Interpretation of educational measurements. Yonkers-on-Hudson, NY: World Book Company.

Krueger, R. F., Derringer, J., Markon, K. E.,Watson, D., \& Skodol, A. E. (2012). Initial construction of a maladaptive personality trait model and inventory for DSM-5. Psychological Medicine, 42, 1879-1890.

Lilienfeld, S. O.,Watts, A. L., \& Smith, S. F. (2012). The DSM revision as a social psychological process: A commentary on Blashfield and Reynolds. Journal of Personality Disorders, 26, 830-834.

McFarland, L. A. (2013). Applicant reactions to personality tests: Why do applicants hate them? In N. D. Christiansen, \& R. P. Tett (Eds.), Handbook of personality at work (pp. 281298). New York, NY: Routledge.

Moyle, P. (1995). The role of negative affectivity in the stress process: Tests of alternative models. Journal of Organizational Behavior, 16, 647-668.

Myors, B., Lievens, F., Schollaert, E., van Hoye, G., Croneshaw, S., Mladinic, A., ... Sackett, P. R. (2008). International perspectives on legal issues in employee selection. Industrial and Organizational Psychology: Perspectives on Science and Practice, 1, 206-246.

Organ, D. W., \& Ryan, K. (1995). A meta-analytic review of attitudinal and dispositional predictors of organizational citizenship behavior. Personnel Psychology, 48, 775-802.

Quirk, S. W., Christiansen, N. D., Wagner, S. H., \& McNulty, J. L. (2003). On the usefulness of measures of normal personality for clinical assessment: Evidence of incremental validity of the Revised NEO Personality Inventory. Psychological Assessment, 15, 311-325.

Samuel, D. B., \& Widiger, T. A. (2008). A meta-analytic review of the relationships between the five-factor model and DSM-IV-TR personality disorders: A facet level analysis. Clinical Psychology Review, 28, 1326-1342.

Sarup, G. (1978).Historical antecedents of psychology: The recurrent issue of old wine in new bottles. American Psychologist, 34, 478-485.

Schmit, M. J., \& Ryan, A. M. (2013). Legal issues in personality testing. In N. D. Christiansen, \& R. P. Tett (Eds.), Handbook of personality at work (pp. 525-542). New York, NY: Routledge.

Shoss, M. K., \& Witt, L. A. (2013). Trait interactions and other configural approaches to personality. In N. D. Christiansen, \& R. P. Tett (Eds.), Handbook of personality at work (pp. 392-418). New York, NY: Routledge. 
Soroka v. Dayton Hudson Corp. 6 Ind. Empl. Rights Case (BNA) 1491 (Cal. Ct. App. 1991).

Stabile, S. J. (2002). The use of personality tests as a hiring tool: Is the benefit worth the cost? University of Pennsylvania Journal of Labor \& Employment Law, 4, 279-313.

Strack, S. (2006). Differentiating normal and abnormal personality (2nd ed.). New York, NY: Springer.

Tett, R. P., Simonet, D. V., Walser, B., \& Brown, C. (2013). Trait activation theory: Applications, developments, and implications for person workplace fit. In N. D. Christiansen, \& R. P. Tett (Eds.), Handbook of personality at work (pp. 71-100). New York, NY: Routledge.

Thimm, J. C. (2011). Incremental validity of maladaptive schemas over five-factor model facets in the prediction of personality disorder symptoms. Personality and Individual Differences, 50, 777-782.

Watson, D., Stasik, S. M., Ro, E., \& Clark, L.A. (2013). Integrating normal and pathological personality: Relating the DSM-5 trait-dimensional model to general traits of personality. Assessment, 20, 312-326.

Widiger, T. A., Costa, P. T., Jr., \& Samuel, D. B. (2006). Assessment of maladaptive personality traits. In S. Strack (Ed.), Differentiating normal and abnormal personality (2nd ed., pp. 311-335). New York, NY: Springer.

Wille, B., De Fruyt, F., \& De Clercq, B. (2013). Expanding and reconceptualizing aberrant personality at work: Validity of five-factor model aberrant personality tendencies to predict career outcomes. Personnel Psychology, 66, 173-223. 